\title{
Acción bioxidativa de cultivos microbianos biolixiviantes sobre la arsenopirita
}

\author{
Biooxidative action of biolixiving microbial crops on arsenopyrite \\ ${ }^{1, a, d}$ Daladier Castillo Cotrina \\ ${ }^{1, b, e}$ Roberto Castellanos Cabrera \\ ${ }^{2, c}$ Ely Tirado Rebaza
}

\begin{abstract}
ARTÍCULO ORIGINAL
${ }^{1}$ Departamento de Biología. Universidad Nacional Jorge Basadre Grohmann, Tacna, Perú.

${ }^{2}$ Universidad Nacional Jorge Basadre Grohmann. Escuela de Biología Microbiología. Tacna, Perú.

Correspondencia:

adcastilloc@unjbg.edu.pe

rcastellanosc@unjbg.edu.pe

cely.tirado.rebaza@gmail.com

ORCID: 0000-0003-0133-5921

'ORCID: 0000-0002-9021-412X

Palabras clave: Acidithiobacillus

\section{RESUMEN}

La arsenopirita es una fuente mineral para la recuperación de oro puro. Sobre ella se emplea la biooxidación, tecnología muy poco estudiada y aplicada en nuestro país a pesar que es de bajo costo, eficiente y amigable con el ambiente. Este trabajo tuvo como objetivo evaluar el grado de biooxidación en dos diferentes concentraciones de arsenopirita por cultivos microbianos de colección que previamente fueron adaptados al $1 \%$ de arsenopirita en el medio de cultivo $0 \mathrm{~K}$. La arsenopirita se tamizó en un tamice Tyler menor de 200 y se agregó en concentraciones de 8 y $12 \%$ en los biorreactores que contuvieron $700 \mathrm{ml}$ de medio fermentativo $(630 \mathrm{ml}$ de medio de cultivo esterilizado con $70 \mathrm{ml}$ de inóculo microbiano). El inóculo estuvo formado por suspensiones de un cultivo microbiano puro y de uno mixto (dos cultivos puros). La incubación se desarrolló a temperatura de ambiente durante 288 horas con aireación. Se evaluó el crecimiento microbiano, $\mathrm{pH}$, hierro total, hierro II, hierro III y la formación de biofilm sobre la superficie de la arsenopirita. Se determinó que el cultivo microbiano mixto actuando sobre la arsenopirita al $8 \%$ produjo el mayor grado de biooxidación correspondiente a una producción de $8197.7 \mathrm{mg} \mathrm{L}^{-1}$ de hierro III.
\end{abstract} ferrooxidans, Acidithiobacillus thiooxidans, arsenopirita, biooxidación.

Keywords: Acidithiobacillus ferrooxidans, Acidithiobacillus thiooxidans, arsenopirirta, biooxidation

Información adicional

Presentado: 17/05/2021

Aprobado: 11/06/2021

\section{ABSTRACT}

Arsenopyrite is a mineral source for the recovery of pure gold, biooxidation is used on it, a technology very little studied and applied in our country although it is low cost, efficient and friendly to the environment. The objective of this work was to evaluate the degree of biooxidation in two different concentrations of arsenopyrite by collection microbial cultures that were previously adapted to $1 \%$ arsenopyrite in the $0 \mathrm{~K}$ culture medium. The arsenopyrite was sieved on a tyler sieve smaller than 200 and added in concentrations of 8 and $12 \%$ in the bioreactors containing $700 \mathrm{ml}$ of fermentation medium $(630 \mathrm{ml}$ of sterilized culture medium with $70 \mathrm{ml}$ of microbial inoculum). The inoculum consisted of suspensions of a pure microbial culture medium one (two pure cultures). The incubation proceeded at room temperature for 288 hours with aeration. Microbial growth, $\mathrm{pH}$, total iron, iron II, iron III, and biofilm formation on the arsenopyrite surface were evaluated. It was determined that the mixed microbial culture acting on $8 \%$ arsenopyrite produced the highest degree of biooxidatio corresponding to a production of $8197.7 \mathrm{mg} \mathrm{L}^{-1}$ of iron III. 


\section{INTRODUCCIÓN}

La biominería contempla la aplicación de distintas tecnologías y procesos hidrometalúrgicos a través del uso de microorganismos para la extracción o disolución de metales de interés económico a partir de minerales o sólidos, con la finalidad de recuperar los elementos deseados (Brierley \& Le Roux, 1978; Panyushkina, et al., 2020). Múltiples microorganismos participan en los procesos de extracción de metales de interés económico a partir de yacimientos o concentrados minerales de baja ley. Esto conlleva a que los microorganismos tengan potenciales aplicaciones (Lundgren \& Silver, 1980; Bosecker, 1997; Cuba \& Pastrana, 2018) y posibles características ambientales benignas (Modak et al., 1999).

El término biooxidación es usado cuando el elemento a recuperar no puede ser solubilizado por los microorganismos, pero su presencia beneficia la recuperación del mismo, a través de la degradación de la matriz mineral en la que está ocluido el elemento de interés (Donati, 2006; Cuba \& Pastrana, 2018). Es llamada también oxidación bacteriana, un proceso en el cual ciertos microorganismos oxidan los sulfuros a través de mecanismos de acción directa e indirecta. Estos microorganismos utilizan como fuente primaria de energía las especies reducidas de hierro, azufre, y el $\mathrm{CO}_{2}$ como fuente de carbono para su síntesis celular; generando durante el proceso grandes cantidades de ácido y arsénico (Rodríguez et al., 2001), asimismo, energía exotérmica (Bulaev et al., 2020).

Los géneros microbianos Acidithiobacillus y Leptospirillum son los más relevantes dentro del proceso de la biooxidación, ya que se hallan de modo natural en los depósitos de minerales y catalizan la solubilización de los sulfuros metálicos por reacciones de oxidación para utilizar la energía química liberada en su metabolismo (Leuze \& Farrow, 2011; Ordoñez, 2017). Otros microorganismos también reportados como biooxidantes son Sulfobacillus, Ferroplasma y Acidiplasma (Bulaev et al., 2020).

La arsenopirita (FeAsS) es la fuente mineral de arsénico más común en la superficie terrestre. Se le encuentra en una variedad de sistemas como depósitos magmáticos, hidrotermales y pórfidos, entre otros. Está comúnmente asociada a la aparición de oro, generando su amplia explotación y posterior descarga como desechos sólidos en los procesos mineros (Corkhill \& Vaughan, 2009; Deng et al., 2020). Es un mineral estable bajo condiciones reductoras, pero oxidativo en condiciones de intemperismo, liberando durante este proceso $\mathrm{H}_{2} \mathrm{SO}_{4}, \mathrm{H}_{3} \mathrm{AsO}_{3} \mathrm{y} \mathrm{H}_{3} \mathrm{AsO}_{4}$ (Nesbitt et al., 1995). Es el más común como portador de sulfuro, y muy frecuente en la superficie terrestre (Corkhill \& Vaughan, 2009). Encapsula en su matriz elementos valiosos como el oro, sea en la forma de pequeñas inclusiones (Márquez, 1999) o como oro invisible (Márquez et al., 2006), lo cual hace que la mayoría de las veces la cianuración de estos minerales requiera largos periodos de exposición, obteniéndose un material de mayor costo (Suzuki, 2001; Zhao et al., 2020).

En la minería es usual la dificultad de la extracción de oro en minerales refractarios que contienen arsénico, como es el caso de la arsenopirita, debido a que no permite la mayor recuperación de este elemento económicamente importante como es el oro. Las bacterias biooxidantes A. ferrooxidans y A. thiooxidans utilizan como fuente de energía compuestos inorgánicos, $A$. ferrooxidans oxida fierro y azufre elemental, $A$. thiooxidans oxida solo azufre elemental (Cuba \& Pastrana, 2018). La oxidación de los iones que realizan estas bacterias provoca que haya una disolución del mineral, lo que hace que el oro que se encuentra asociado a la matriz del mismo sea expuesto, de tal modo que durante el proceso de cianuración, que es posterior a la biooxidación haya una mayor recuperación de oro (Deng et al., 2020; Zhao et al., 2020).

Acidithiobacillus thiooxidans y Acidithiobacillus ferrooxidans son dos bacterias que tienen características diferentes. Son producto de una reclasificación, intervienen en la oxidación de hierro asociada a la formación de drenajes ácidos de minería y aumentan la oxidación y solubilización de los sulfuros presentes en los drenajes ácidos en las minas de carbón (Colmer \& Hinkle, 1947). Uno de estos microorganismos fue considerado responsable de la oxidación del $\mathrm{Fe}^{+2} \mathrm{a} \mathrm{Fe}^{+3}$, al cual llamaron Thiobacillus ferrooxidans (Colmer \& Hinkle, 1947; Temple \& Colmer, 1950) que después fue reclasificada como Acidithiobacillus ferrooxidans (Kelly \& Wood, 2000). Es una bacteria aerobia, con forma de bastón y flagelo polar, Gram negativa, asporulada, con dimensiones de $0.5 \mu \mathrm{m}$ de ancho y 1.0 a $2.0 \mu \mathrm{m}$ de largo con extremos redondeados (Rossi, 1990), mesófilo, con capacidad de catalizar la oxidación de sulfuros 
metálicos por el mecanismo directo y el mecanismo indirecto (Torma, 1977). Acidithiobacillus thiooxidans inicialmente conocida como Thiobacillus thiooxidans (Waksman \& Joffe, 1922) fue después reclasificada como Acidithiobacillus thiooxidans (Kelly \& Wood, 2000); es una bacteria Gram negativa en forma de barra con extremos redondeados; con 0.30 a $0.60 \mu \mathrm{m}$ de ancho por 0.90 a $3.00 \mu \mathrm{m}$ de largo; se adapta a $\mathrm{pH}$ menores a 2 con un óptimo de trabajo de $\mathrm{pH} 1.8$; trabaja a temperaturas de entre 20 a $30^{\circ} \mathrm{C}$. Obtiene su energía a través de compuestos inorgánicos de azufre elemental, sulfuro de hidrógeno, tiosulfato y otros compuestos reducidos de azufre. Se le considera como el responsable de la rápida disolución de los sulfuros metálicos (Chen \& Lin, 2004; López et al., 2007; Mejía, 2010; Ordoñez, 2017). Poblaciones compuestas por A. ferrooxidans y A. thiooxidans en minerales de cobre han mostrado altas recuperaciones de cobre durante la lixiviación (Khalid \& Malik, 1988; Falco et al., 2003).

La biooxidación en minerales de oro refractarios como el de la arsenopirita es un método prometedor para la recuperación del oro que puede encontrarse como partículas microscópicas, es de fácil funcionamiento con bajo costo y ecoamigable (Deng et al., 2020; Zhao et al., 2020). Su aplicación en concentrados de arsenopirita aurífera empleando microorganismos quimiolitotróficos acidófilos está considerado entre los procesos comerciales más importantes (Panyushkina et al., 2020).

Un microorganismo puede diferir en capacidades de acción entre especies y dentro de una misma especie. Asimismo, cuando el substrato procede de lugares diferentes. En este trabajo los microorganismos estudiados procedieron de la colección alemana de microorganismos DSMZ y el mineral arsenopirita de la Empresa minera Sudoeste S.A. de Oruro, Bolivia.

El presente trabajo tuvo como objetivo determinar el grado de biooxidación del cultivo puro Acidithiobacillus ferrooxidans y del cultivo mixto Acidithiobacillus ferrooxidans con Acidithiobacillus thiooxidans sobre la arsenopirita.

\section{MATERIALES Y MÉTODOS}

\section{Microrganismos y mineral empleado en la investigación}

Se trabajó con los cultivos microbianos Acidithiobacillus ferrooxidans DSMZ 1477 (A.f) y Acidithiobacillus thiooxidans DSMZ 1478 (A.t) procedentes de la Colección Alemana de Microorganismos (DSMZ) y con un concentrado de Arsenopirita (Ars) de la empresa minera sudoeste S.A, Oruro, Bolivia, que tuvo un tamaño de partícula al de las aberturas del tamice Tyler menor a 200; con una composición química formada por Au (81.5g/t), Ag (154 g/t), As (33.8\%), Bi (1.84\%), Cd (0.01\%), C0 (1.4\%), Fe (27.9\%), Ni (1.72\%), Pb (1.21\%), Sb (0.22\%), Zn (2.88\%), Cu (0.07\%), $\mathrm{Al}(0.21 \%)$ y $\mathrm{SiO}_{2}$ $(5.15 \%)$ determinada en el Laboratorio SGS Bolivia S.A y con una composición mineralógica (brindado por la Empresa EMISOL S.A Bolivia), formada por $7 \%$ pirita $\left(\mathrm{FS}_{2}\right), 0.2 \%$ calcopirita $\left(\mathrm{CuFeS}_{2}\right), 4.3 \%$ esfalerita $(\mathrm{ZnS}), 1.6 \%$ galena $(\mathrm{PbS}), 73.5 \%$ arsenopirita (FeAsS $)$ y $13.4 \%$ Ganga.

\section{Reactivación y adaptación de los microorganismos en la Arsenopirita}

Cada cultivo microbiano fue reactivado sometiéndolo a dos cultivos consecutivos. Para el primer cultivo se extrajo $2 \mathrm{ml}$ del cultivo A. ferrooxidans para ser agregado a $25 \mathrm{ml}$ de medio de cultivo $9 \mathrm{~K}-\mathrm{Fe}(0.04$ $\mathrm{gL}^{-1} \mathrm{~K}_{2} \mathrm{HPO}_{4}, 0.4 \mathrm{gL}^{-1} \mathrm{MgSO}_{4} 7 \mathrm{H}_{2} \mathrm{O}, 0.1 \mathrm{gL}^{-1} \mathrm{NH}_{4} \mathrm{SO}_{4} 33.3 \mathrm{gL}^{-1} \mathrm{FeSO}{ }_{4} 7 \mathrm{H} \mathrm{Q}, \mathrm{pH} 1.5$ ajustado con $\mathrm{H} \mathrm{SO}$ ) y $2 \mathrm{ml}$ del cultivo A. thiooxidans para ser inoculado a $25 \mathrm{ml}$ de medio de cultivo $9 \mathrm{~K}-\mathrm{S}\left(0.04 \mathrm{gL}^{-1} \mathrm{~K}_{2}^{2} \mathrm{HPO}_{4}^{4}\right.$, $0.4 \mathrm{gL}^{-1} \mathrm{MgSO}_{4} \cdot 7 \mathrm{H}_{2} \mathrm{O}, 0.1 \mathrm{gL}^{-1} \mathrm{NH}_{4} \mathrm{SO}_{4} 5.0 \mathrm{gL}^{-1} \mathrm{~S}, \mathrm{pH} 1.5$ ajustado con $\mathrm{H}_{2} \mathrm{SO}_{4}$ ) (Kim et al., 2002). Los medios de cultivo sembrados se incubaron a $25^{\circ} \mathrm{C}$ con aireación hasta que se obtuvo una concentración de $10^{8}$ células $\mathrm{ml}^{-1}$ con la ayuda de una cámara de Neubauer y de un microscopio de campo claro (Pavez, 2011). Para el segundo cultivo, en ambos microorganismos se inoculó $25 \mathrm{ml}$ del primer cultivo a $225 \mathrm{ml}$ de medio de cultivo nuevo y se incubó a $25^{\circ} \mathrm{C}$ con aireación hasta que se alcanzó una concentración de $10^{8}$ células ml ${ }^{-1}$ (Diana et al., 2005). Los componentes químicos de los medios de cultivo fueron proporcionados por el Laboratorio de Micología-Virología de la UNJBG que a su vez los obtuvo del Laboratorio Merck. Los 
cultivos microbianos reactivados fueron sometidos a un proceso de adaptación previo a su uso en la experimentación. El 10\% del cultivo microbiano (V/V) fue inoculado en $600 \mathrm{ml}$ de medio de cultivo $0 \mathrm{~K}$

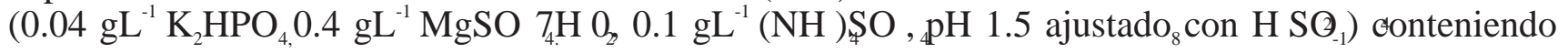
arsenopirita al $1 \%(\mathrm{~W} / \mathrm{V})$ e incubado a $25^{\circ} \mathrm{C}$ con aireación hasta que alcanzó 10 células $\mathrm{ml}$.

\section{Experimentación y toma de datos}

Se estableció como tratamientos para el inicio de la experimentación a T1 (A. ferrooxidans con arsenopirita 8\%), T2 (A. ferrooxidans con arsenopirita 12\%), T3 (A. ferrooxidans con A. thiooxidans y arsenopirita 8\%), y T4 (A.ferrooxidans con A. thiooxidans y arsenopirita 12\%) (Ayala \& Pardo, 1995). Cada tratamiento tuvo dos repeticiones. Los biorreactores empleados fueron frascos de vidrio de $1000 \mathrm{~cm}^{3}$. En el biorreactor del tratamiento T1 y T2 se agregó $630 \mathrm{ml}$ de medio de cultivo $0 \mathrm{~K}$ previamente autoclavado y 70 $\mathrm{ml}$ de inóculo de A. ferrooxidans con 8 y $12 \%$ (W/V) de arsenopirita respectivamente. En el biorreactor del T3 y T4 se agregó $630 \mathrm{ml}$ del medio de cultivo $0 \mathrm{~K}, 35 \mathrm{ml}$ de inóculo de $A$. ferrooxidans con $35 \mathrm{ml}$ de inóculo de A. thiooxidans con 8 y $12 \%(\mathrm{~W} / \mathrm{V})$ de arsenopirita respectivamente. Los biorreactores fueron incubados a $25^{\circ} \mathrm{C}$ con aireación durante 288 horas. Se tomaron muestras cada 48 horas para determinar la concentración microbiana con una cámara de Neubauer y un microscopio de campo claro; el pH con un pHmetro digital marca Hanna Instruments; la concentración de hierro total, hierro II y hierro III con un espectrofotómetro en el cual se determinaron las absorbancias de las muestras que a su vez fueron llevadas a una curva de calibración para que en ella se determinara la concentración de hierro en función del valor de absorbancia. Al final de la experimentación se evaluó la formación de biofilm sobre las partículas de arsenopirita con un microscopio electrónico de barrido (marca TESKAN, modelo Vega II) perteneciente a la Escuela Profesional de Ingeniería Metalúrgica de la UNJBG.

\section{Tratamiento de los datos y análisis estadístico}

Los datos de concentración microbiana, $\mathrm{pH}$ y de concentración de hierro fueron graficados relacionándolos con el tiempo de incubación en el que estuvieron los biorreactores. Los datos de hierro II oxidados fueron sometidos al análisis de varianza y la prueba de Duncan para el establecimiento del tratamiento con mayor grado de biooxidación. Las observaciones de las superficies de las partículas de arsenopirita fueron evidenciadas obteniendo fotomicrografías para su análisis (Arroyave et al., 2009).

\section{RESULTADOS}

La mayor concentración celular se alcanzó cuando el cultivo microbiano fue mixto (A.f+A.t) y cuando estuvo con arsenopitita al 8\%, tanto en un cultivo puro (A.f) o en un cultivo mixto. La mayor concentración microbiana fue $2.12 \times 10^{8}$ células $\mathrm{ml}^{-1}$ a las 240 horas. El cultivo mixto con arsenopirita al $12 \%$ alcanzó una concentración de $1.54 \times 10^{8}$ células $\mathrm{ml}^{-1}$ a las 192 horas. El cultivo puro con arsenopirita al $8 \%$ alcanzó el valor de $1.12 \times 10^{8}$ células $\mathrm{ml}^{-1}$ a las 240 horas, y el cultivo puro con arsenopirita $12 \%$ el valor de $8.65 \times 10^{7}$ células $\mathrm{ml}^{-1}$ a las 288 horas. Los mayores valores de concentración celular que se obtuvieron en los cultivos mixtos se presentaron antes que el de los cultivos puros (Tabla 1) (Figura 1). 


\section{Tabla 1}

Valores promedio de concentración celular de cultivos puros (A.f) y mixtos $(A . f+A t)$ en medio de cultivo sumergido con arsenopirita al 8 y $12 \%$ en función del tiempo.

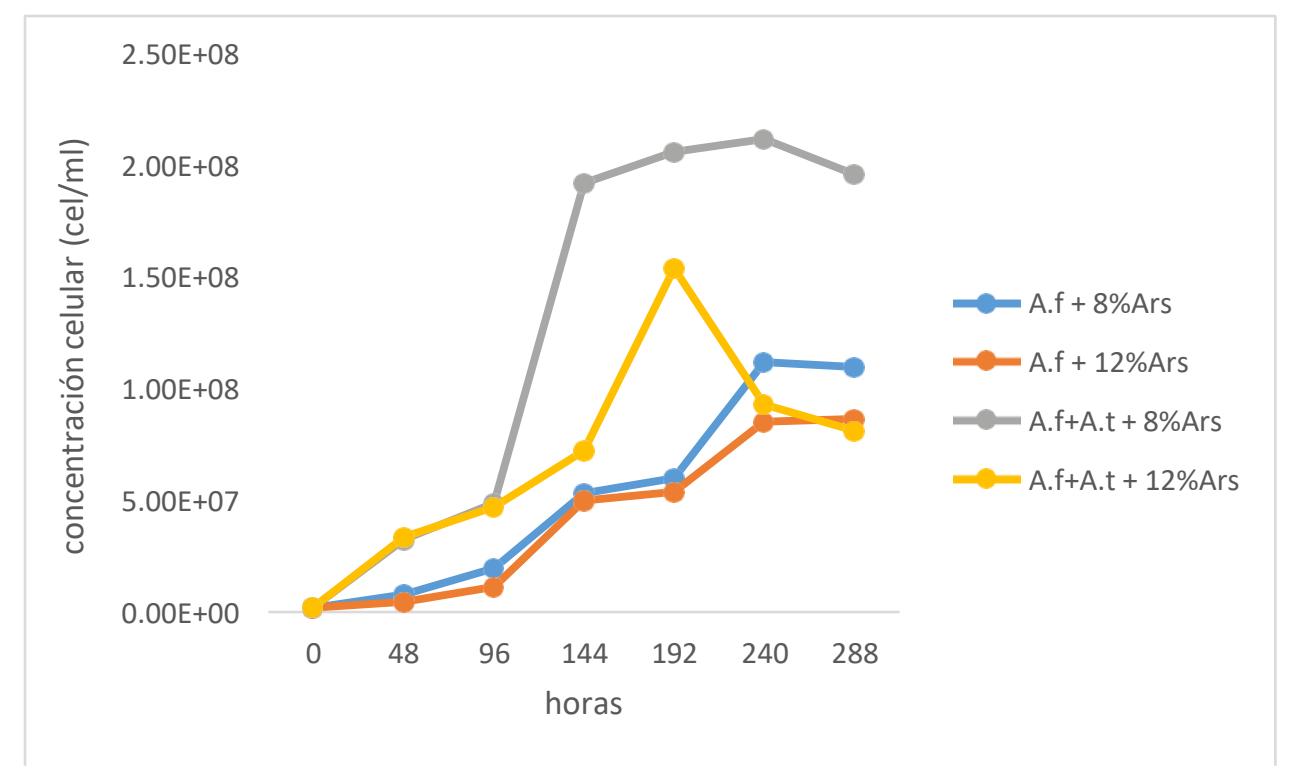

Figura 1. Crecimiento microbiano de cultivos puros (A.f) y mixtos (A.f+At) en medio de cultivo sumergido con arsenopirita al 8 y $12 \%$ en función del tiempo.

Los cultivos mixtos (A.f+A.t) y puros (A.f) mostraron un incremento de $\mathrm{pH}$ en función del tiempo, apreciándose los mayores valores de $\mathrm{pH}$ en los cultivos mixtos, con 2.13 como valor más alto a las 240 horas en el cultivo mixto con arsenopirita $12 \%$. El cultivo mixto con arsenopirita $8 \%$ mostró como valor más alto de $\mathrm{pH}$ a 2.12 a las 240 horas, el cultivo puro con arsenopirita $8 \%$ el valor de 1.72 a las 192 horas, y el cultivo puro con arsenopirita $12 \%$ el valor de 1.67 a las 96 horas. El rango de $\mathrm{pH}$ alcanzado en el cultivo mixto con arsenopirita $12 \%$ fue de 1.68 a 2.13 y con arsenopirita $8 \%$ fue de 1.68 a 2.12 , y en el cultivo puro con arsenopirita $12 \%$ fue de 1.5 a 1.67 y con arsenopirita $8 \%$ fue de 1.5 a 1.72 (Figura 2 ).

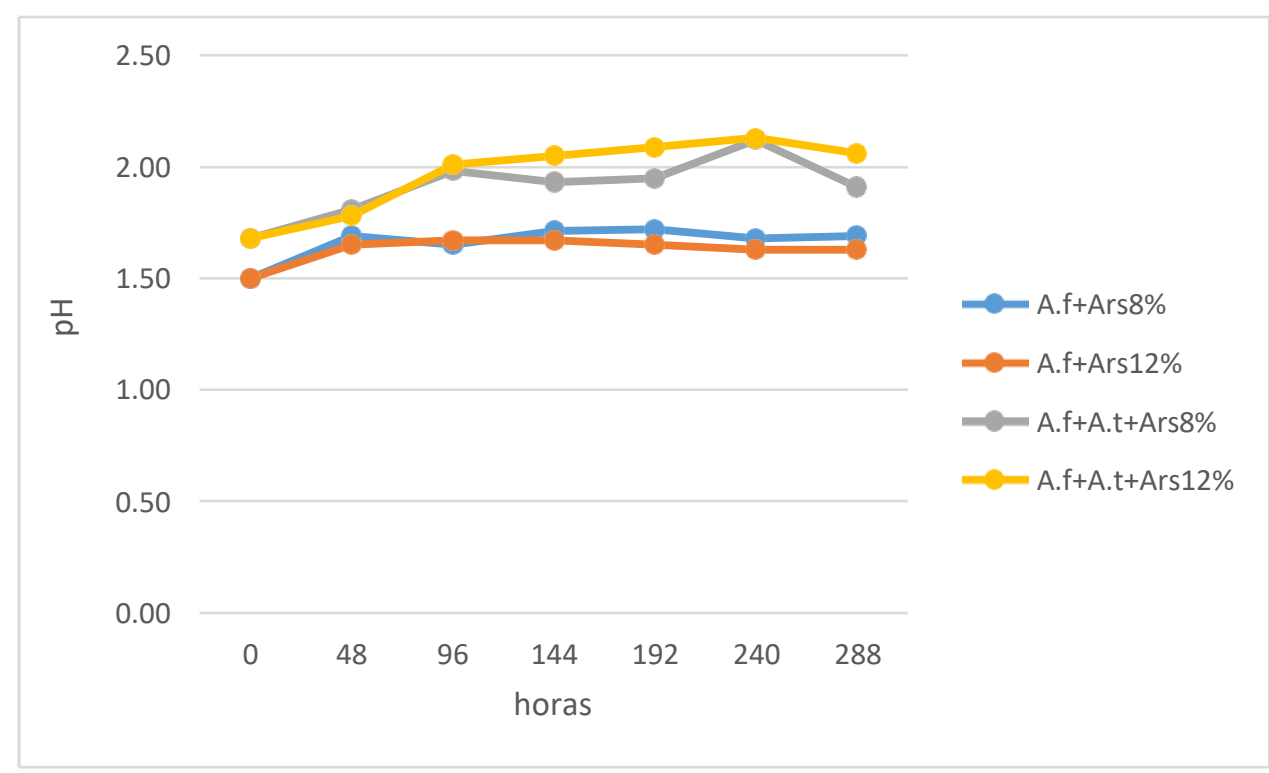

Figura 2. Evolución del pH de cultivos puros (A.f) y mixtos (A.f+A.t) en cultivos sumergidos con arsenopirita al 8 y $12 \%$ en función del tiempo. 
El cultivo microbiano puro con arsenopirita 8\% ejerció acción biooxidativa sobre el hierro II de la arsenopirita desde el inicio hasta el final de la experimentación, siendo en esta última etapa donde se produjo la mayor biooxidación del hierro II, 1524.2 $\mathrm{mg} \mathrm{ml}^{-1}$ a las 288 horas (Figura 3).

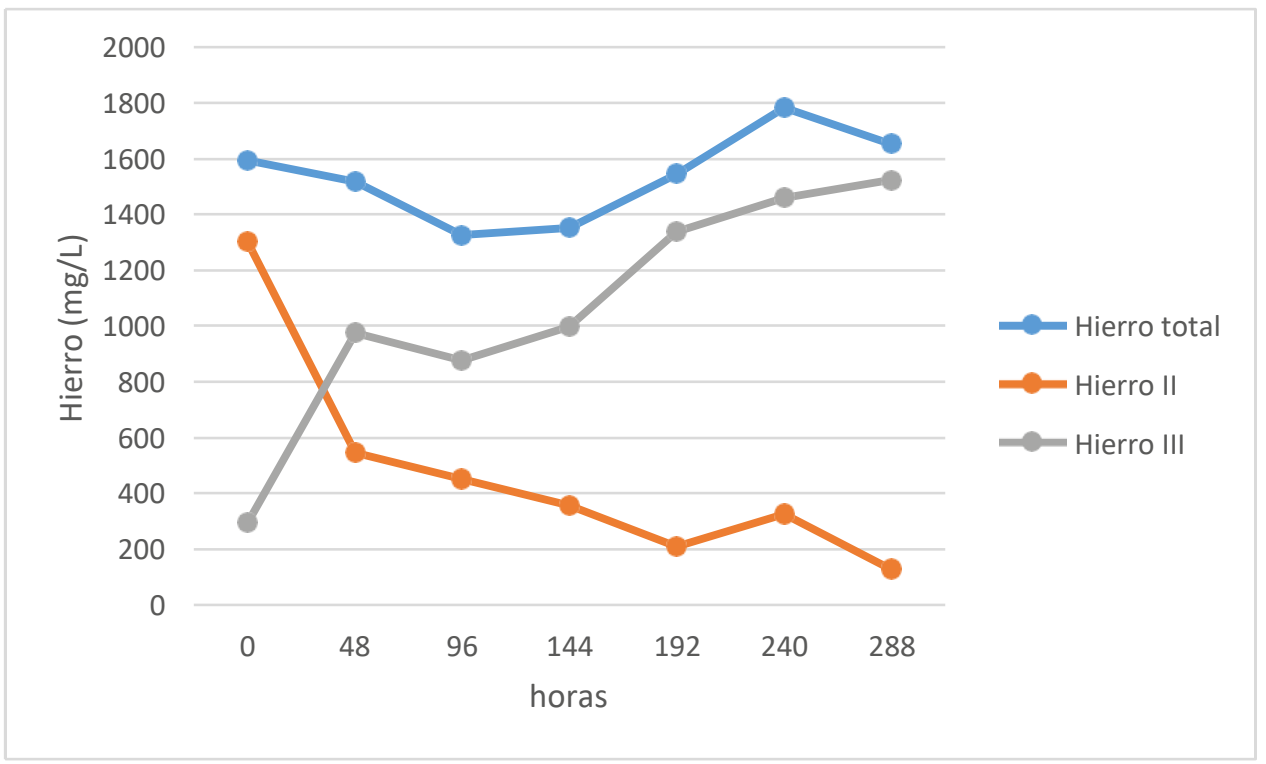

Figura 3. Evolución del hierro total, hierro II y hierro III en función del tiempo de experimentación por la acción de biooxidación del cultivo microbiano puro (A.f) sobre la arsenopirita $8 \%$.

El cultivo microbiano puro con arsenopirita al 12\% ejerció acción biooxidativa sobre el hierro II de la arsenopirita desde el inicio hasta el final de la experimentación siendo en esta última etapa donde se produjo la mayor biooxidación del hierro II, $1320.9 \mathrm{mg} \mathrm{ml}^{-1}$ a las 240 horas (Figura 4).

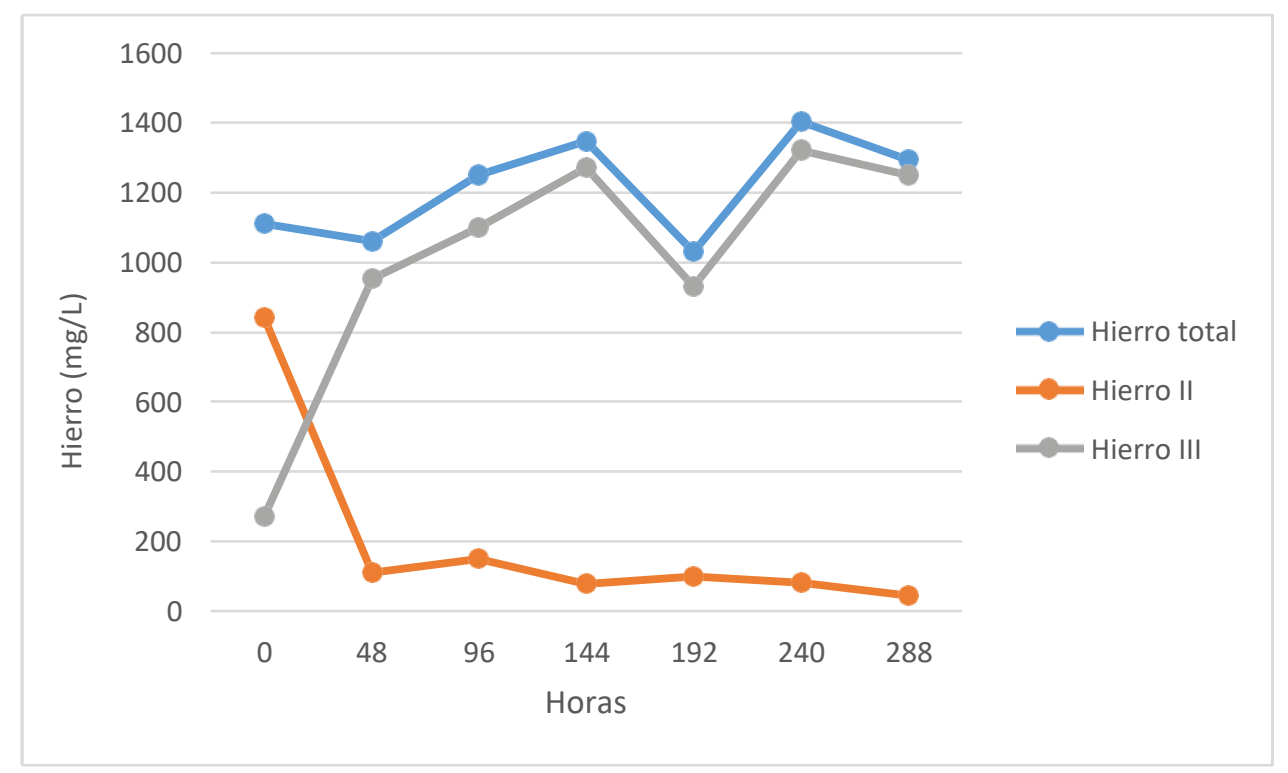

Figura 4. Evolución del hierro total, hierro II y hierro III en función del tiempo de experimentación por la acción de biooxidación del cultivo microbiano puro (A.f) sobre la arsenopirita $12 \%$.

El cultivo microbiano mixto con arsenopirita 8\% ejerció acción biooxidativa sobre el hierro II de la arsenopirita desde el inicio hasta el final de la experimentación, siendo en esta última etapa donde se produjo la mayor biooxidación del hierro II, $8197.7 \mathrm{mg} \mathrm{ml}^{-1}$ a las 144 horas (Figura 5). 


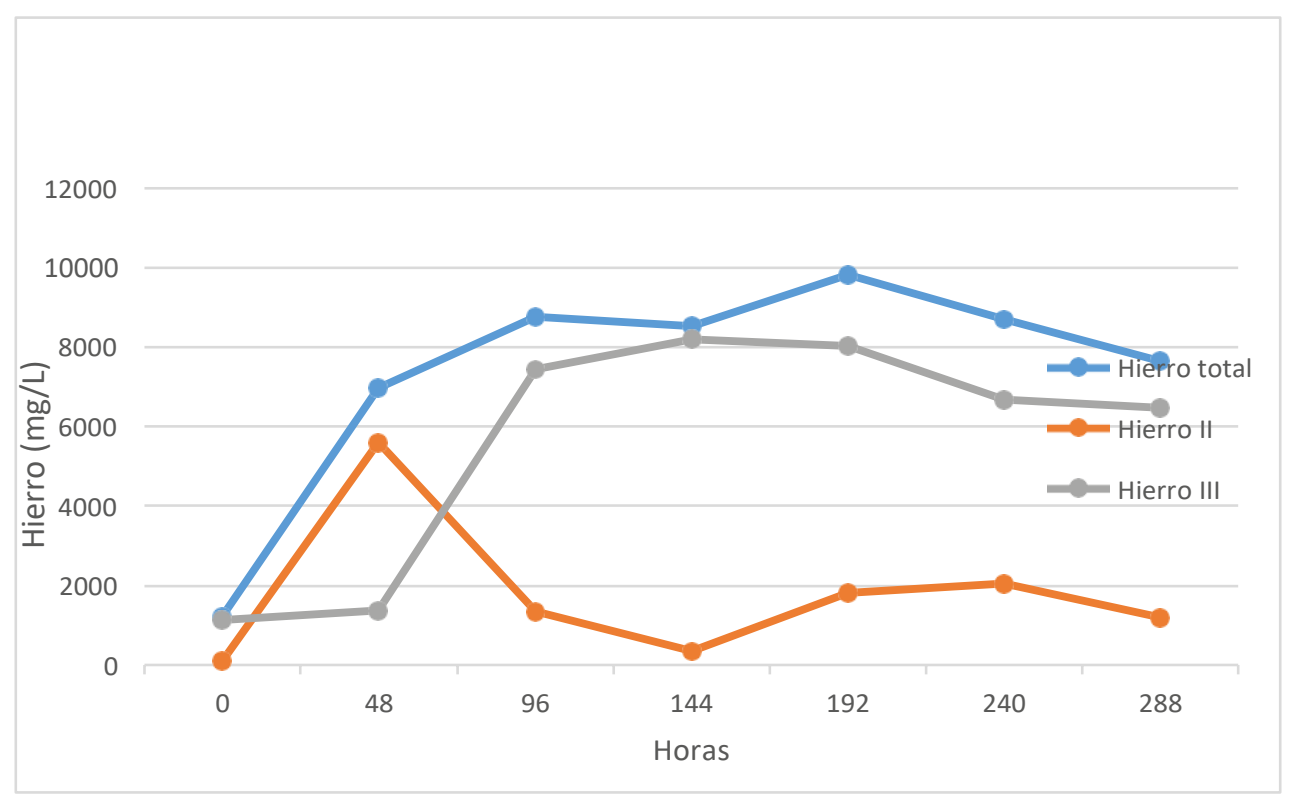

Figura 5. Evolución del hierro total, hierro II y hierro III en función del tiempo de experimentación por la acción de biooxidación del cultivo microbiano mixto (A.f+A.t) sobre la arsenopirita 8\%.

El cultivo microbiano mixto con arsenopirita 12\% ejerció acción biooxidativa sobre el hierro II de la arsenopirita desde el inicio hasta el final de la experimentación, siendo en esta última etapa donde se produjo la mayor biooxidación del hierro II, 7209.3 $\mathrm{mg} \mathrm{ml}^{-1}$ a las 192 horas (Figura 6).

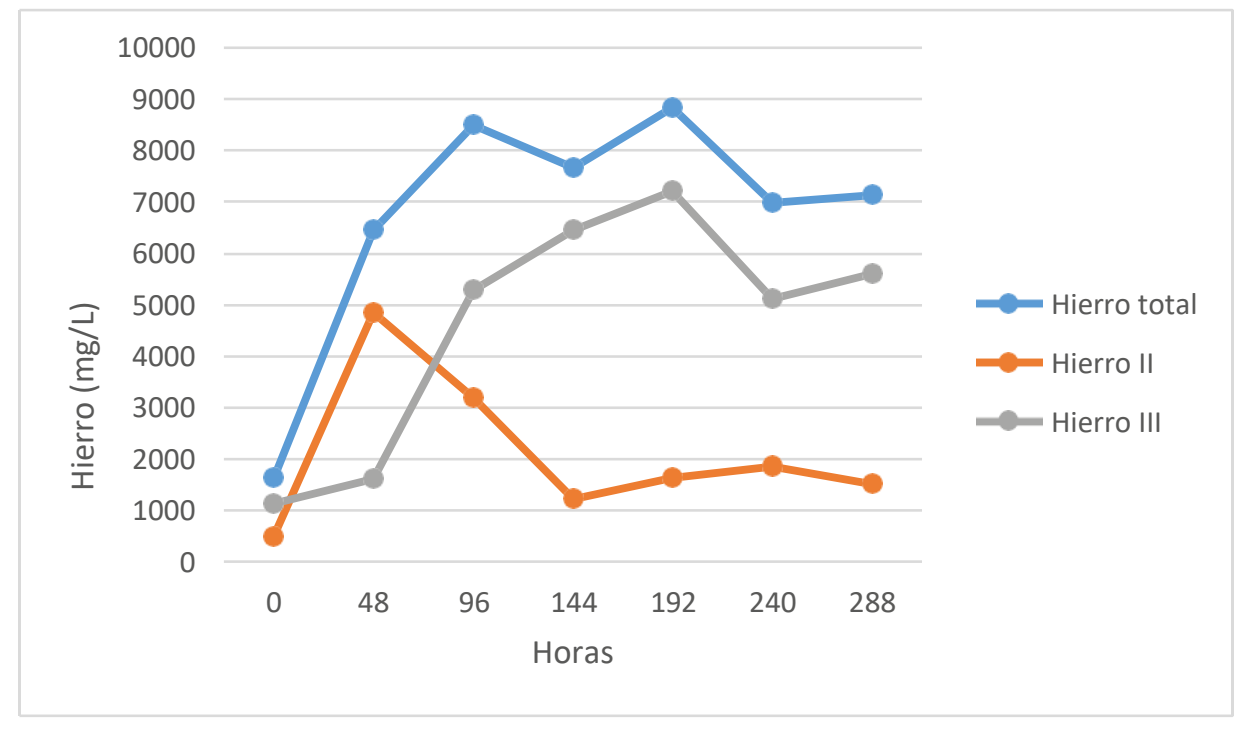

Figura 6. Evolución del hierro total, hierro II y hierro III en función del tiempo de experimentación por la acción de biooxidación del cultivo microbiano mixto (A.f+A.t) sobre la arsenopirita $12 \%$. 
Los cultivos microbianos mixtos originaron mayores valores de concentración de hierro III respecto a los cultivos puros, presentando el más alto valor de concentración de hierro III $\left(8197.7 \mathrm{mg}\right.$. $\left.\mathrm{L}^{-1}\right)$ el cultivo mixto con arsenopirita al 8\%. Según el análisis de varianza y la prueba de Duncan, se estableció que luego del valor más alto de hierro III estuvieron el cultivo mixto con arsenopirita $12 \%$ (7209.3 $\left.\mathrm{mg} \mathrm{L}^{-1}\right)$, el cultivo puro con arsenopirita $8 \%\left(1524.2 \mathrm{mg} \mathrm{L}^{-1}\right.$ ) y el cultivo puro con arsenopirita $12 \%$ (1320.95 $\mathrm{mg} \mathrm{L}^{-1}$ ) (Figura 7 ).

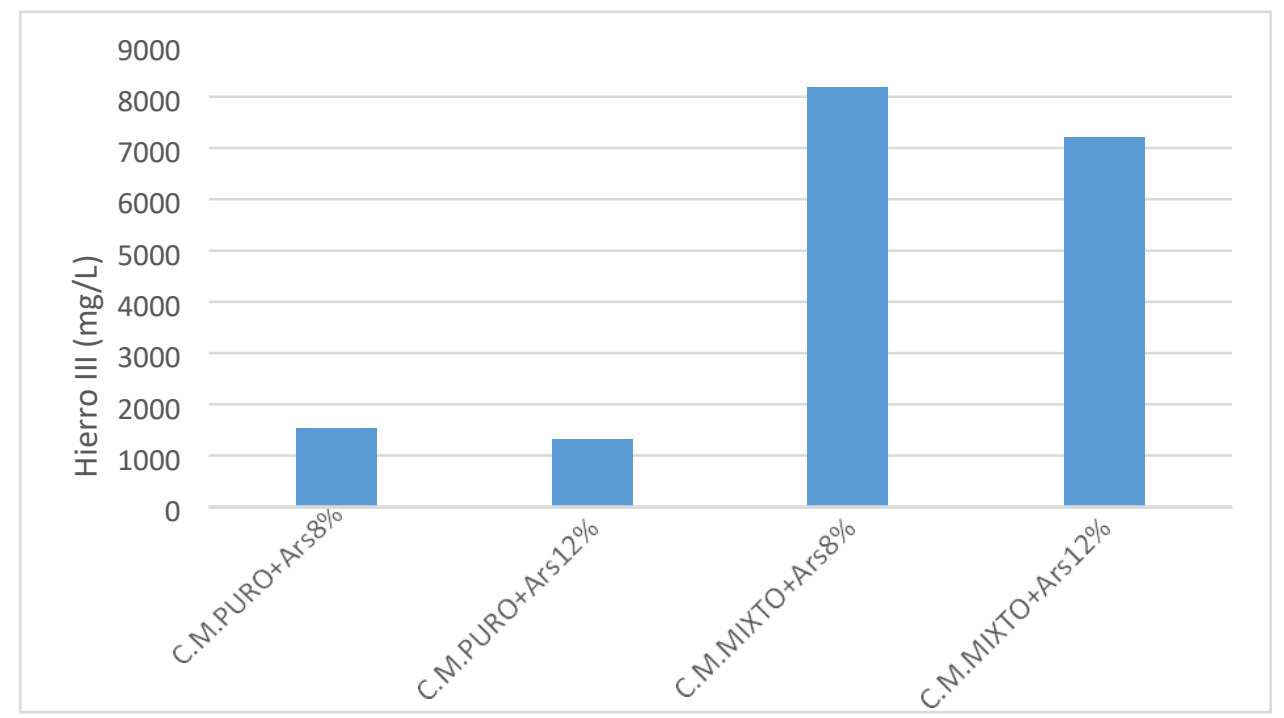

Figura 7. Concentraciones de hierro III más altos producidos por los cultivos microbianos puros (A.f) y mixtos (A.f+A.t) por su acción biooxidativa sobre el hierro II de la arsenopirita al 8 y $12 \%$.

En la Figura 8 se muestra biopelículas microbianas junto a precipitados (cristales) sobre las superficies de hendiduras en partículas de arsenopirita extraídas del cultivo mixto (A.f + A.t) con arsenopirita $12 \%$ al final de la experimentación, 288 horas, como evidencia de la acción biooxidativa de $A$. ferrooxidans y de A. thiooxidans sobre el hierro de la arsenopirita.

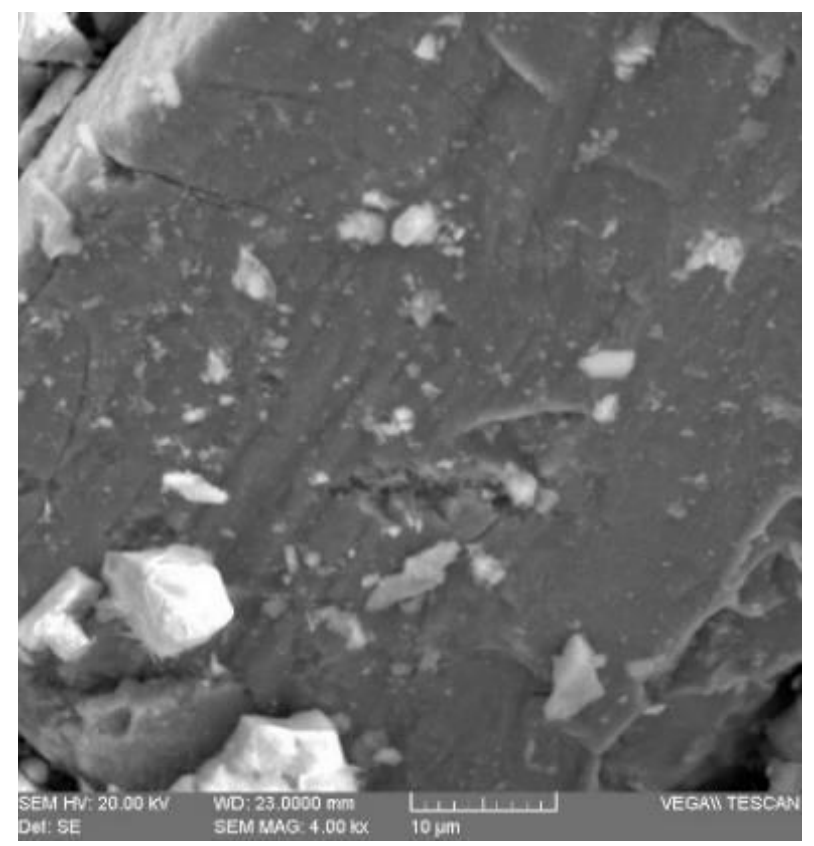

Figura 8. Biopelículas microbianas y precipitados producto de la bioxidación del hierro en las partículas de la arsenopirita extraídas del cultivo microbiano mixto (A.f+A.t+Ars 12\%) observadas en el microscopio electrónico de barrido. 


\section{DISCUSIÓN}

En este trabajo, Acidithiobacillus ferrooxidans (A.f) y Acidithiobacillus thiooxidans (A.t) como cultivos puros (A.f) o mixtos (A.f+A.t) oxidaron el hierro de la arsenopirita. Estos microorganismos podrían utilizarse para recuperar el oro presente en una arsenopirita aurífera. Acidithiobacillus ferrooxidans, bacteria acidófila, mesófila; es muy utilizada en biominería, emplea al azufre y al hierro como fuente de energía. Acidithiobacillus thiooxidans, bacteria acidófila, emplea como fuente de energía al azufre (Gilbert et al., 1988; Daoud \& Karamanev, 2006; Corkhill \& Vaughan, 2009).

La ausencia de la fase de latencia o de adaptación en el inicio de las curvas de crecimiento microbiano de los cultivos puros (A.f) y mixtos (A.f+A.t) es probable que se deba a la adaptación a la que fueron sometidos A. ferrooxidans y A. thioxidans en arsenopirita $1 \%$, que fue previa e inmediata a la experimentación, lo que explica que se tuviera una continuación de la fase logarítmica de las curvas de crecimiento. Cuando un microorganismo se encuentra en fase logarítmica en un determinado medio de cultivo y es transferido a un mismo medio de cultivo, pero renovado el microorganismo, continúa en fase logarítmica. Esto es importante porque para la disolución de metales se requiere microorganismos adaptados previamente al ambiente específico para obtener buenos resultados (Barrie, 2006). La concentración de arsenopirita, $1 \%$, empleada para la adaptación de A. ferrooxidans y A. thioxidans estuvo basada en que la adaptación de los microorganismos en arsenopirita puede darse entre 1 y $5 \%$ (W/V) (Masoon \& Rice, 2002; Deveci et al., 2004; Shi \& Fang, 2005; Shi et al., 2006; Astudillo \& Acevedo, 2008). Este proceso además de acortar la fase de latencia de la curva de crecimiento es importante en la obtención de mayores valores de concentración microbiana, el mayor valor obtenido en este trabajo fue

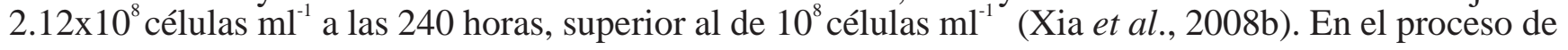
adaptación no hay un protocolo definido, a veces es necesario una adaptación de años (Brahmaprakash et al., 1988; Natarajan etal., 1994; Das etal., 1998).

Los mayores valores de concentración microbiana observados en los cultivos microbianos mixtos es probable que sean por una relación de sinergismo. Los microorganismos involucrados $A$. ferrooxidans y $A$. thiooxidans al estar como cultivo mixto interactúan de tal modo que la concentración microbiana es mayor que en cultivos puros. El mayor crecimiento de los cultivos microbianos mixtos fue entre las 192 y 240 horas de incubación, mucho antes que el de los cultivos puros entre las 240 y 288 de incubación, siendo importante como característica de productividad para una posible aplicación como tecnología minera. La tendencia de disminución en el cultivo mixto al final de la experimentación es probable que se deba al incremento de hierro, producto de la biooxidación, y otros iones en solución como $\mathrm{As}^{3+}, \mathrm{As}^{5+} \mathrm{y} \mathrm{Fe}^{3+}$, que se ven concentrados por la reducción de oxígeno debido al consumo del mismo por los microorganismos, lo que provoca fricción a la pared celular disminuyendo o inhibiendo la actividad microbiana (Gómez et al., 1999; Akcil et al., 2007; Mousavi et al., 2007; Marhual et al., 2008).

El pH inicial de 1.5 en los cultivos puros y de 1.67 en los cultivos mixtos favoreció la experimentación. Los microorganismos de los cultivos tuvieron condiciones favorables para la biooxidación del hierro II. Cuando el pH es menor a 1.8, la precipitación de hierro III es limitada (Gómez \& Cantero, 2005; Daoud \& Karamanev, 2006). El incremento de 0.56 de pH en los cultivos mixtos y de 0.22 en los cultivos puros se explica porque el concentrado de mineral trabajado tiene varios elementos químicos que al ir liberándose paralelo al proceso biooxidativo alcalinizaron el medio del cultivo aumentando el $\mathrm{pH}$. El incremento de $\mathrm{pH}$ se puede deber a la disolución de ciertos minerales no metálicos acompañantes del mineral de arsenopirita (Rossi, 1990).

En este trabajo los cultivos microbianos mixtos por haber producido mayores concentraciones de hierro III (8197.7 y $7209.3 \mathrm{mg}$. $\mathrm{L}^{-1}$ ) son los que realizaron un mejor proceso de biooxidación del hierro II contenido en la arsenopirita, por lo cual el cultivo mixto Acidithiobacillus ferrooxidans con Acidithiobacillus thiooxidans son consorcios potenciales para su aplicación como tecnología minera sobre concentrados de arsenopirita. Las mezclas de microorganismos que se emplean en la oxidación de la arsenopirita muestran una fuerte complementariedad con mejores resultados que los cultivos puros (Tuovinem et al., 1994; Clark \& Norris, 1996; Chiacchiarini et al., 2000; Mc Guire et al., 2001). Las mayores concentraciones de hierro III obtenido en los cultivos mixtos y puros, cuando la arsenopirita 
estuvo en la concentración de $8 \%$ y no en el $12 \%$, es probable que se deba a que aquí es menor la concentración de los metales tóxicos, lo que hace que los microorganismos ejerzan mayor acción biooxidativa sobre el hierro II de la arsenopirita.

Los pequeños agujeros observados sobre la superficie de las partículas de arsenopirita son llamados golfos de corrosión producto de la acción biooxidativa de los microorganismos acidófilos que a su vez coadyuvan a que se formen cristales como productos secundarios de la solubilización (Arroyave $e t$ al., 2009). Las capas de microorganismos (biofilms) formados sobre la superficie de la arsenopirita constituyen parte del mecanismo biooxidativo por contacto directo, a través del cual los microorganismos se adhieren a la superficie de la arsenopirita para la oxidación del hierro; por tanto, aumentar la capacidad de incrementar la formación de biofilm en estos microorganismos es sugerente para una mejor efectividad.

\section{CONCLUSIONES}

Los cultivos mixtos de Acidithiobacillus ferrooxidans y A. thiooxidans con arsenopirita 8\% produjeron mayor biooxidación del hierro II $\left(8197.7 \mathrm{mg}\right.$. $\left.\mathrm{L}^{-1}\right)$ que cuando estuvieron como cultivos puros, por lo cual estos microorganismos como cultivo mixto constituyen un recurso biológico potencial como tecnología minera. 


\section{REFERENCIAS}

Arroyave, D., Márquez, M., Gallego, D., \& Pacheco, G. (2011). Evaluación y caracterización mineralógica del proceso de biooxidación en un reactor continuo de tanque agitado. Dyna, 77(164), 18-29.

Ayala, J., \& Pardo, R. (1995). Optimización por Diseños Experimentales con Aplicaciones en Ingeniería. Lima: CONCYTEC.

Bosecker, K. (1997). Bioleaching: metal solubilization by microorganisms. FEMS Microbiology reviews, 20(3-4), 591-604.

Brahmaprakash, G. P., Devasia, P., Jagadish, K. S., Natarajan, K. A., \& Rao, G. R. (1988). Development of Thiobacillus ferrooxidans ATCC 19859 strains tolerant to copper and zinc. Bulletin of Materials Science, 10(5), 461-465.

Brierley, C. L., \& Le Roux, N. W. (1978). Bacterial leaching. CRC critical reviews in microbiology, 6(3), 207-262.

Bulaev, A., Melamud, V., \& Boduen, A. (2020). Bioleaching of non-ferrous metal from arsenic-bearing sulfide concentrate. Solid state phenomena, 299.

Chiacchiarini, P., De la Fuente, V., \& Donati, E. (2000). Pre-tratamiento de un mineral refractario de oro mediante células de Thiobacilli.

Colmer, A. R., \& Hinkle, M. E. (1947). The role of microorganisms in acid mine drainage: a preliminary report. Science, 106(2751), 253-256.

Corkhill, C. L., \& Vaughan, D. J. (2009). Arsenopyrite oxidation. Applied Geochemistry, 24 (12), 23422361. https://doi.org/10.1016/j.apgeochem.2009.09.008

Cuba, M., \& Pastrana, G. (2018). Recuperación de oro a partir de un mineral refractario de pirrotita por biooxidación en la biominería aurífera Calpa-Arequipa (tesis para obtener el título profesional). Universidad Nacional del Centro del Sur. Huancayo.

Daoud, J., \& Karamanev, D. (2006). Formation of jarosite during $\mathrm{Fe}^{2+}$ oxidation by A. ferrooxidans. Minerals Engineering, 19(9), 960-967.

Das, A., Modak, J. M., \& Natarajan, K. A. (1998). Studies on multi-metal ion tolerance of Thiobacillus ferrooxidans. Minerals Engineering, 10(7), 743-749.

Deng, Y., Zhang, D., Xia, J., Nie, Z., Liu, H., Wang, N., \& Xue, Z. (2020). Enhancement of arsenopyrite bioleaching by different $\mathrm{Fe}$ (III) compounds through changing composition and structure of passivation layer. Journal of Materials Research and Technology, 9(6).

Deveci, H., Akcil, A., \& Alp, I. (2004). Bioleaching of complex zinc sulphides using mesophilic and thermophilic bacteria: comparative importance of $\mathrm{pH}$ and iron. Hydrometallurgy, 73(3), 293-303.

Donati, E. (2006). Biominería: Una tecnología alternativa. http://www.voces.antahualan.com.ar/edi11.htm

Gilbert, S. R., Bounds, C. O., \& Ice, R. R. (1988). Comparative economics of bacterial oxidation and roasting as a pre-treatment step for gold recovery from an auriferous pyrite concentrate. Can. Min. Metall. Bull., 81(910), 89-94.

Kelly, D. P., \& Wood, A. P. (2000). Reclassification of some species of Thiobacillus to the newly designated genera Acidithiobacillus gen. nov., Halothiobacillus gen. nov. and Thermithiobacillus gen. nov. International Journal of Systematic and Evolutionary Microbiology, 50(2), 511-516. 
Khalid, Z. M., \& Malik, K. A. (1988). Leaching of chalcopyrite by Thiobacillus thiooxidans and oxidized copper ore by Thiobacillus ferrooxidans isolated from local environments. MIRCEN journal of applied microbiology and biotechnology, 4(4), 447-453.

Leuze, J.A. De. \& Farrow, B. A. (2011). Modulación de Biopelículas de microorganismos para lixiviación de minerales.

López, T., Domínguez, L., \& García, J. (2007). Arreglo estructural de un consorcio microbiano de interés alimentario en la producción del vinagre. Trabajo presentado en el octavo Congreso Nacional de Microscopía. México.

Lundgren, D. G., \& Silver, M. (1980). Ore leaching by bacteria. Annual Reviews in Microbiology, 34(1), 263-283.

Márquez, M. (1999). Mineralogia dos processos de oxidação sobre pressãoe bacteriana do minerio de ouro da mina São Bento. MG (Tese de doutorado). Universidad de Brasilia.

Márquez, M., Gaspar, J., Bessler, K. E., \& Magela, G. (2006). Process mineralogy of bacterial oxidized gold ore in São Bento Mine (Brasil). Hydrometallurgy, 83(1), 114-123.

Mason, L. J., \& Rice, N. M. (2002). The adaptation of Thiobacillus ferrooxidans for the treatment of nickel-iron sulphide concentrates. Minerals Engineering, 15(11), 795-808.

Mejía, E. (2010). Mineralogía del proceso de lixiviación bacteriana de calcopirita $\left(\mathrm{CuFeS}_{2}\right)$, esfarelita $(\mathrm{ZnS})$ y galena $(\mathrm{PbS})$ (tesis de maestría). Universidad Nacional de Colombia. Colombia

Modak, J. M, Vassan, S. S., \& Natarajan, K. (1999). Calcium removal from bauxite using Paenibacillus polymyxa. Minerals and Metallurgical Process, 16(4), 6-12.

Mousavi, S. M., Jafari, A., Yaghmaei, S., Vossoughi, M., \& Roostaazad, R. (2007). Bioleaching of lowgrade sphalerite using a column reactor. Hydrometallurgy, 82, 75-82.

Natarajan, K. A., Sudeesha, K., \& Rao, G. R. (1994). Stability of copper tolerance in Thiobacillus ferrooxidans. Antonie van Leeuwenhoek, 66(4), 303-306.

Ordoñez, J. (2017). Producción de sustancias poliméricas extracelulares de los microorganismos acidófilos Leptospirillum ferrooxiodans y Acidithiobacillus thiooxidans en medio puro y modificado con un mineral aurífero refractario (tesis de titulación). Universidad Técnica Particular de Loja. Ecuador.

Panyushkina, A., Matyushkina, D., \& Pobeguts, O. (2020). Understanding stress response to high-arsenic gold-bearing sulfide concéntrate in extremely metal - resistant acidophile Sulfobacillus thermotolerans. Microorganisms, 8, 1076.

Pavez, B. (2011). Cuantificación de la expresión del gen omp-40 y de los genes que conforman el operón gal, vinculado a cambios cinéticos de Acidithiobacillus ferrooxidans en respuesta adaptativa a mineral sulfurado de cobre (tesis para optar el título de Bioquímico).

Rodríguez, Y., Ballester, A., Blázquez, M. L., González, F., \& Muñoz J. A. (2001). Mecanismo de biolixiviación de sulfuros metálicos. Revista de metalurgia, 37(6), 665-672.

Rossi, G. (1990). Biohydrometallurgy. McGraw-hill.

Shi, S., \& Fang, Z. (2005). Bioleaching of marmatite flotation concentrate by adapted mixed mesoacidophilic cultures in an Air-lift reactor. International Journal of Mineral Processing. 76, $3-12$.

Suzuki, I. (2001). Microbial leaching of metals from sulfide minerals. Biotechnology advances, 19(2), 119-132.

Temple, K. L., \& Colmer, A. R. (1951). The autotrophic oxidation of iron by a new bacterium: Thiobacillus ferrooxidans, Journal of bacteriology. 605-611. 
Torma, A. (1977). The role of Thiobacillus ferrooxidans in hydrometallurgical processes. Advances in Biochemical Engineering, 6, 1-37. Springer Berlin Heidelberg.

Tuovinen, O. H., Niemelä, S. I., \& Gyllenberg, H. G. (1971). Tolerance of Thiobacillus ferrooxidans to some metals. Antonie van Leeuwenhoek, 37(1), 489-496.

Zhao, H., Yang, H., Tong, L., Zhang, Q., \& Kong, Y. (2020). Biooxidation-thiosulfate leaching of refractory gold concentrate. International Journal of minerals, metallurgy and materials, 27(8) 1075. 